\title{
US government approves transgenic chicken
}

The eggs of the genetically engineered animal contain an enzyme that can treat a rare disease.

\section{Rachel Becker}

09 December 2015

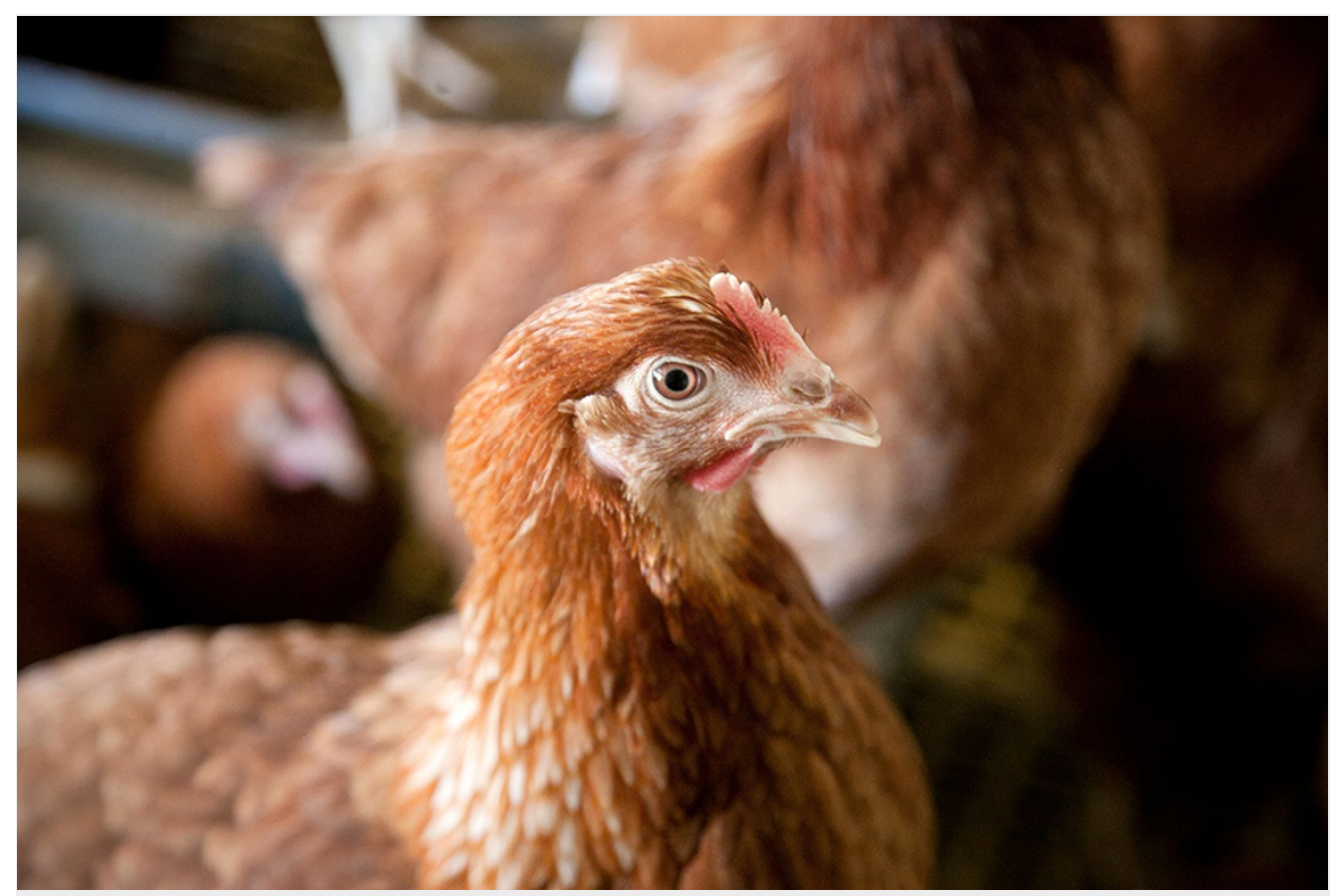

Manu Palomeque/Alamy

Transgenic chickens are the latest animals engineered to produce 'farmaceutical' drugs.

The US Food and Drug Administration (FDA) has approved a chicken that has been genetically engineered to produce a drug in its eggs.

The drug, Kanuma (sebelipase alfa), is a recombinant human enzyme marketed by Alexion Pharmaceuticals. It replaces a faulty enzyme in people with a rare, inherited condition that prevents the body from breaking down fatty molecules in cells.

Following its approval by the FDA on 8 December, Kanuma joins a small group of 'farmaceuticals' on the US market. In 2009, the agency approved genetically modified goats that produce an anticoagulant called ATryn (antithrombin) in their milk. And last year, the FDA authorized a drug for treating hereditary angioedema that is produced by transgenic rabbits.

The FDA's latest decision "shows that the ATryn goats weren't just a one-off", says Jay Cormier, a lawyer at Hyman, Phelps and McNamara in Washington DC and a former scientific reviewer for the FDA. "The process can function for more than just one particular unique case."

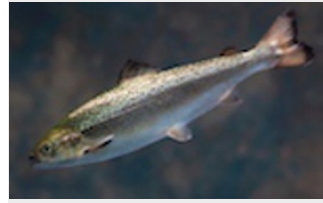

Salmon is first transgenic animal to win US approval for food

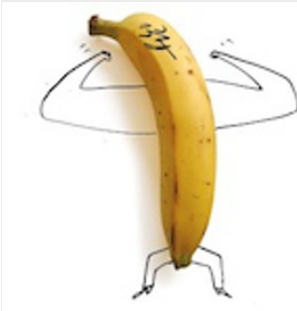

Transgenics: A new breed biochemical defect in the disorder," says Barbara Burton, a paediatrician with the Northwestern University Feinberg School of Medicine in Chicago, Illinois. Clinicians could only provide nutrition and supportive care to infants, says Burton, who worked with Alexion to conduct the clinical trials. Older patients are treated with statins - which do not 
address the fatty build-up in the liver.

\section{Not for eating}

Unlike the genetically engineered AquAdvantage salmon that was approved by the FDA last month, the transgenic chickens that produce Kanuma are not intended to enter the food supply. But just as with the AquAdvantage salmon, the FDA considers the chicken's genetic modifications to be an 'animal drug'.

Because every cell in the modified chicken contains altered DNA, the FDA "asserts its jurisdiction over the entire chicken", says Cormier.

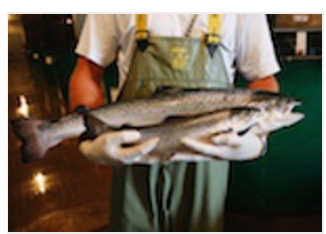

Salmon approval heralds rethink of transgenic animals

Under its process for considering animal drugs, the FDA examined whether altering the chickens' DNA would harm them, and whether the modified DNA was stable as it passed to new generations of chickens. The FDA says that the chickens are not likely to accidentally enter the food supply or adversely affect the environment because they are raised in indoor facilities.

William Muir, a geneticist at Purdue University in West Lafayette, Indiana, praised the FDA's decision to approve the transgenic chickens. "The floodgates are opening," he says, "and I can't wait to see what comes next."

Nature I doi:10.1038/nature.2015.18985 